\title{
Disaster management policy and conflict resolution: a case study of South Korea's dam construction
}

\author{
Y. J. Kim \\ National Disaster Management Institute (NDMI), South Korea
}

\begin{abstract}
The aim of this article is to extract the factors for successful conflict resolution by analyzing the multi-stakeholders' conflict framing and the course of conflicts in the context of dam construction as one of the measures of disaster mitigation. The author examined the stakeholders, perceptual framing and conflict resolution mechanism of the conflict in the process of constructing Hantan River dam of South Korea. The results suggest that the personnel in charge 1) establish joint fact-finding procedures, 2) expand citizen participation in policy making by sharing information, 3) coordinate inter-agency, 4) enact related Acts to develop long-term measures for the residents and 5) create a standard manual of conflict in the context of disaster for a successful completion of the relevant projects in the future.
\end{abstract}

Keywords: disaster management policy, conflict resolution, ADR, dam, Hantan River, Dong River.

\section{Introduction}

Concern about occurrence of various catastrophes result from climate change has surfaced as a serious issue in the world. Since 1990s, Korea has experienced a variety of conflicts emerged as a consequence of great disasters or in the process of decision making and implementing disaster policies (e.g. dam construction as one of the measures of disaster mitigation). However the fundamental importance of the systematic approach like understanding people's perception to build consensus that integrates the different views among the affected groups of interest has largely been ignored. Given my desire to know what conflict partners are perceiving and thinking about the interaction and how these differences in 
perception and definition affect conflict management (Sillars et al. [13]), it is appropriate to investigate the ways in which people articulate their conceptualizations of interpersonal conflicts.

As such, this article employed the conflict framing to examine the stakeholder, perceptual framing and conflict resolution mechanism of the conflict in the process of constructing Hantan River dam of South Korea. The used research method involves a review and analysis of documents such as daily newspapers between 2001 and 2009, official documents, and so on. Face to face interviews with interested parties were also conducted. The author asked them to reflect upon their experiences of working and activities and what they felt were its benefits and negative aspects.

\section{Theoretical framework}

\subsection{Conflict and framing}

Scholars of communication and conflict are in general agreement that conflict can be conceptualized as an expressed struggle between two or more interdependent parties who perceive goal incompatibility, scarce resources, and interference from the other party in their individual goal achievement $[2,5]$. Scholars tend to be in further agreement that perception is the most central variable in both the creation and management of conflict interaction Randall [12].

Broadly speaking, framing is the process by which people individually define and assign meaning to a class of objects, persons, and events (Randall [12]). In recent years, framing has become a popular concept among scholars of conflict and negotiation $[7,11]$.

\subsection{Approaches to Research on Framing}

Putnam and Holmer [11] identify three separate orientations to framing research: the cognitive heuristic approach, the frame categories approach, and the issue development orientation. To begin, the cognitive heuristics orientation focuses on how individuals make decisions about management strategies according to the perceived benefits and losses associated with particular options (Blount and Larrick [1]). This line of inquiry has generally explored the static individual biases and decision-making structures that influence negotiation behavior.

According to the frame categories line of research, frames are internal expectancy sets that individuals employ to make sense of an existing interaction. Researchers working in this realm have principally investigated the types of frames individuals use to define their conflicts and the relationship of frames to outcome goals and expected satisfaction (Pinkley [10]). They initially posit six types of categories: (1) substantive frames define what the conflict is about, (2) loss-gain frames provide interpretations associated with the risk or benefits of various outcomes, (3) characterization frames are expectations and evaluations of the other disputants' behaviors and attitudes, (4) process frames are expectations 
about how the negotiation will or should proceed, (5) aspiration frames express the disputants' underlying interests and needs, (6) outcome frames are the disputants' preferred positions or solutions (Gray et al. [6]).

The third orientation is the issue development approach (Drake and Donohue [3]). Similar to the frames as categories perspective, the issue development orientation focuses on communicators' discourse to glean insight into how parties use frames to define a conflict event. Yet unlike the frames as categories orientation, issue development researchers focus on how frames are developed, negotiated, and transformed during the course of interaction. Research from this perspective has explored the ways in which disputants individually define the topic of the conflict and how those definitions are negotiated with the other party (Drake and Donohue [3]). Of particular interest to this investigation are the frame categories and issue development areas of research.

\section{Research Framework}

The conflict framing can be conceptualized according to Figure 1. Drawing on frame categories, this study employed loss-gain frames, characterization frames, process frames and fact-relevance frames to analyze the characteristics of the course of conflicts and their settlements in the cases of Hantan River dam in Korea. Fact-relevance frames are new ones the author added through a review of documents. They express the disputants' different points of view in phenomena due to scientific uncertainties. Dam construction involves various interested groups(government, NGOs, citizens, etc.) with divergent interests and experiences that make the implementation process complicated: (1) the Ministry of Construction and Transportation ("MoCT"); (2) the Korea Water Resource Corporation ("KWRC") which together with the Ministry was in charge of dam construction; (3) people living in the Dam site and downstream ("PD"); (4) people living in the upper stream area of the Hantan River Dam site ("PU"); (5) NGOs for environmental movements;(6) local government ("LG"); (7) people living in submerged districts("PSD"); (8) the Ministry of Environment("ME"). In general, the MoCT, KWRC, and PD were in favor of dam construction, while the PU, NGOs and ME were opposed. The LG and PSD took both positions.

\section{A case study of Hantan River dam conflict}

\subsection{Background}

The Hantan River is a main tributary of the Imjin River, which is $253.6 \mathrm{~km}$ long and drains 21 major watersheds in the trans-boundary area between South and North Korea. The Han River originates from Pyonggang county in North Korea and flows into the Imjin River at Yeoncheon county in South Korea near the DMZ running through Chulwon and Pocheon. The Hantan River is $144 \mathrm{~km}$ long (86 km in South Korea, $55 \mathrm{~km}$ in North Korea) and accounts for 30 percent of the Imjin River's basin area. 


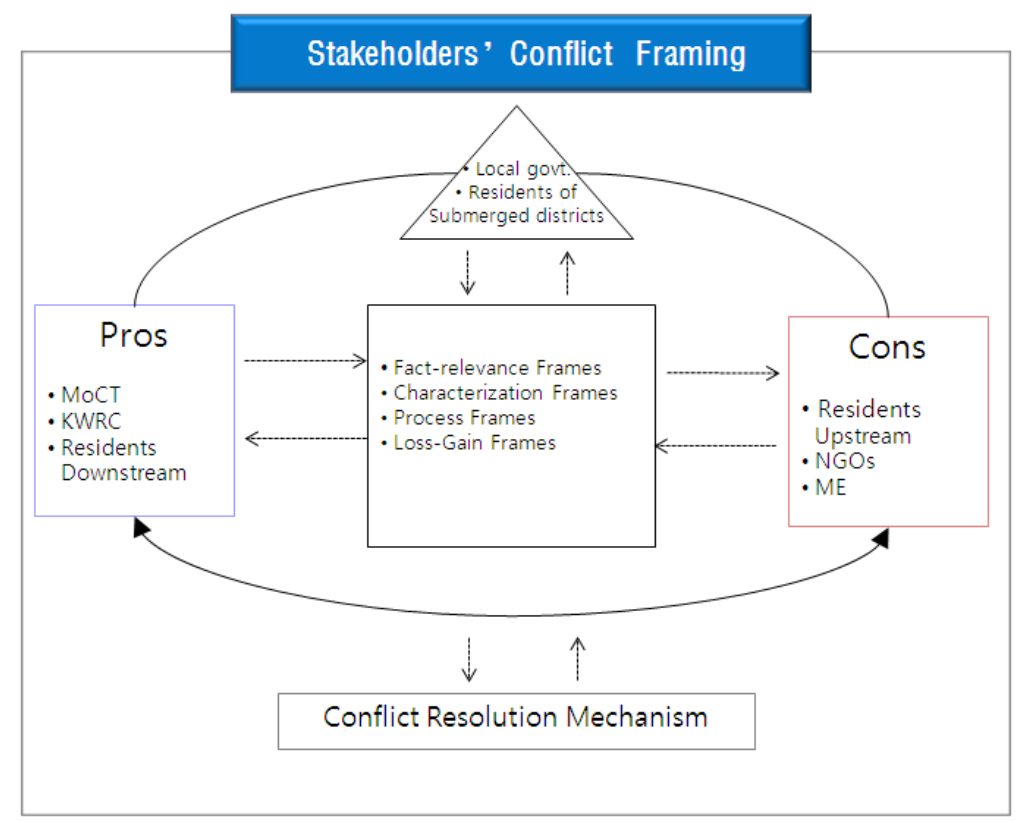

Figure 1: Conflict framing.

The Hantan River dam was planned in 1999 as a flood prevention measure after large-scale floods in the late 1990s. In 1996, a concentrated rainfall measuring over $600 \mathrm{~mm}$ in the Hantan river basin overwhelmed the Yeoncheon dam's flood control volume and flooded the downstream region. Shortly thereafter, the dam collapsed. In August 1998, a surprising record rainfall fell across Korea, which affected 14,776 people and caused 310 billion won of property damage along the Imjin River. In 1999, in the Imjin river basin, a rainfall of over $700 \mathrm{~mm}$ destroyed Yeoncheon dam once again, and caused severe flood damage in Moonsan and Yeoncheon. The three floods together killed 128, affected 31,439 others, and caused 900 billion won in property damage along the Imjin River PCSD [9].

A plan was to build a dam between Yeoncheon and Pocheon to a height of 85 meters and length of 705 meters in order to control 3.05 million tons of flood volume with 3.11 million tons of water storage capacity. The Ministry of Construction and Transportation (MoCT) officially announced the plan in 2001 as part of the long-term plan of constructing 12 dams nationwide. However, local resistance disrupted the public consultation process. A grassroots networking organization, Hantannet, was established in 2000. It mobilized the anti-dam movement of local communities and a nationwide network organization, People's Action for No Dam (PAND), arose. Experts' assistance regarding technical and scientific issues enabled local people to reveal the contradictions of the plan, which escalated the animosity between the government and communities. 

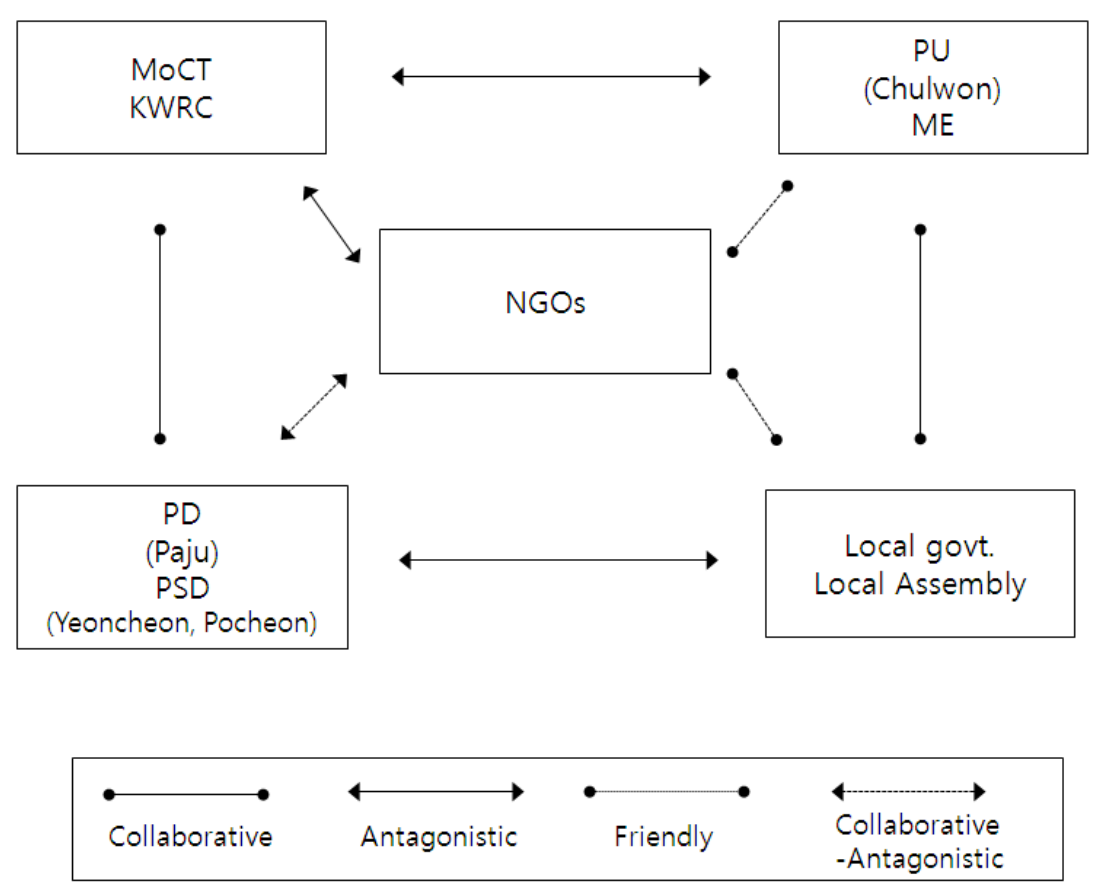

Figure 2: A relation chart among interested parties.

\subsection{Conflict framing}

\subsubsection{Fact-relevance frames}

The conflict was seemingly caused by the Hantan River dam plan, but in substance, the challenge against the dam-centered water supply policy underlies it. Transparency of information and analysis is essential to building and maintaining the trust needed to identify mutual interests. Advocacy science is common in environmental disputes involving complexity and uncertainty (Randall [12]). Public debates had developed for several years partly due to scientific uncertainties, but mostly to the veiled process of data collection and analysis.

The limited public access to information such as the total flood volume and the flood control volume of the dam generated the iterative disagreement about facts and assumptions and further diminished trust between stakeholders and governmental agencies. Above all, the effectiveness of the dam to control flooding of the downstream Imjin River was called into question because the Hantan River occupies only $16.6 \%$ of the Imjin River basin, which means its maximum flood control volume is less than $13.6 \%$ of the total. Moreover, the dam's location, planned to be above the spot at which the Hantan River joins its main tributary, the Youngpyungcheon, indicated that the dam would be too small to control flooding of the bigger river. 
The Korea Water Resources Corporation's (KWRC) frequent changes in basic flood data also escalated mistrust. For example, the flood control volume of the dam upstream was originally $2,560 \mathrm{cms}$, and downstream (Moonsan) was $2,700 \mathrm{cms}$. However, the basin area downstream is six times larger than that upstream. Therefore, the discharge volume downstream should be smaller than that upstream. KWRC adjusted the upstream rainfall from $471 \mathrm{~mm} /$ year to $520 \mathrm{~mm} /$ year in 2000, and again to $568 \mathrm{~mm} /$ year in 2002 to prove the dam's flood control volume to be $2,700 \mathrm{cms}$. Furthermore, the dam's flood control volume was calculated based on very limited hydraulic and watergate data. Political interests and culture, popular attitudes, and laws can trigger environmental conflicts.

\subsubsection{Characterization frames}

Hantan River dam conflict represents the difference in values and collective identity among the bureaucracy, PU or NGOs. Threats to their identity cause severe conflicts and hostility (Randall [12]). Two parties had negative thoughts mutually with respect to characterization frames.

Anti-dam residents asked the government to address procedural and environmental issues of the plan, which in part coincided with the interests of the NGOs. The NGOs refuted the feasibility of the plan based on scientific analysis and procedural legitimacy. The government, however, stuck to the planned dam construction and its procedural rationality as the best option for flood control in the Imjin River basin. While the government considered anti-dam residents as only seeking for compensation, residents and NGOs insisted that the MoCT and KWRC carried forward the dam construction to maintain their organization.

\subsubsection{Process frames}

Historically, the vicious cycle of top-down decision-making and successive failed resolution attempts exacerbated the relationships between communities and the government. Poor participation methods, such as public hearings or consultation, also contributed to the escalating mistrust that hindered appropriate communication. The structural conflict is mainly related to the problem of legitimizing a decision-making process. The top-down policy making prevented deliberation on the alternatives and on the timeline for dam construction. The government preferred a fast track of policy making, hoping thereby to minimize the potential flood damage and the extra costs generated by the project's delay, while residents asked for extended research and resource investment to find the optimal solution.3 The unequal distribution of resources, such as experts, information, and money, also restricted communication between the government and local residents, and hindered their ability to seek common ground. Lastly, the perceived distribution of benefits and costs generated by the dam's construction divided communities.

The public review process of the Environmental Impact Assessment failed to mollify the local population. Public consultation was sought on the plan's first draft in 2001. The Ministry of the Environment completed the review process of the EIA on the third re-submitted plan in December 2003 and recommended two amendments: the water gate was to be open for 350 days of every year so as to 
preserve the ecosystem, and the design of the dam was to be switched from multi-purpose to flood control. The frequent changes made by MoCT over technical issues strained the credibility of the plan, which fueled the anti-dam movement. Local authorities and councils also opposed the dam project and the Gangwon provincial governor officially announced his position against the dam in August 2003, a position prompted by an October 2002 mass rally in Cheolwon.

\subsubsection{Loss-gain frames}

The people in downstream areas who had suffered from repeated flood damage mainly approved of the plan as they anticipated the benefits of flood control, such as an increase in property value and regional economic development. In contrast, the upstream area was largely against the project, because of fear of the economic, environmental, and social costs of dam construction and the introduction of new regulation.

Anti-dam residents also asked the government to address the technological and procedural issues of the plan, which in part coincided with the interests of the NGOs. The NGOs refuted the feasibility of the plan based on scientific analysis, hoping the case would generate momentum to reorient the existing water supply policy. The government, however, stuck to the planned dam construction and its procedural rationality as the best option for flood control in the Imjin River basin.

\subsection{Conflict resolution mechanism}

The ongoing rallies and protests led the National Assembly in 2003 to disapprove the dam construction budget for the next year, but MoCT continued its controversial plan. The conflict reached a turning point on 19 December 2003 when President Roh promised during a dialogue with Gangwon Province residents to reconsider the Hantan River dam project. He ordered the Presidential Committee on Sustainable Development (PCSD) to take charge of the case and to initiate a consensus-building process for conflict resolution. It was expected that its final decision would be accepted by both proponents and opponents if they agreed with the process and the outcome.

As such, PCSD established the action plan, which encompassed organization of a preparation team, process design, organization of a conflict mediation subcommittee, and the mediation process among stakeholders.

However, there were four serious obstacles to mediation. First, there was not enough data on the amount of flooding in the Imjin River, and no way to measure it, because the great majority of the river was in North Korea. Second, local elections of the PU made mediation difficult because political candidates locked themselves into positions opposing the dam. Third, there were communication problems and intransigence. For example, a common communication problem involved a first party raising an issue and a second party providing a solution, but the first party refused to accept the solution due to stubbornness. In effect, the first party lacked confidence and trust in the second party, and maintained an unmoving stance on all issues. Fourth, PU 
representatives had different interests in participating in the mediation process. Some wanted to build their political reputation, while others made efforts to get more benefits for their communities.

As a consequence, the Hantan River dam conflict remained unresolved and went to the Supreme Court in 2007. In 2009, the Supreme Court decided against the plaintiff, namely PU.

\section{Discussion and conclusion}

This case study has examined the multi-stakeholders' conflict framing and the course of conflicts in the context of dam construction as one of the measures of disaster mitigation to extract successful conflict resolution factors. The Hantan River dam conflict is the first case to which a well-designed conflict management process has been applied with political support in Korea. The experiment was not successful, despite certain achievements.

This article has five main findings. One possible starting point for this discussion is to establish joint fact-finding procedures. Joint fact-finding offers an alternative to the process of adversary science when important technical or science-intensive issues are at stake (Ehrmann and Stinson [4]). Scientific information, knowledge and expertise are important sources of power in decision making because they are used to identify a problem and its solutions, and to persuade decision makers to support and choose among the alternatives Ozawa [8]. Joint fact-finding is a central part of the consensus building process for environmental issues involving uncertainty and risks.

Second, the government needs to observe the correct procedures by sharing information and expand citizen participation in policy making to dam construction. Substantive 'Environmental Effects Evaluation' and effective public hearings can be good examples to attain the goal.

Third, closer interagency coordination is required. The MoCT and KWRC consult with the Ministry of Environment and the Ministry of Strategy and Finance to perform 'Environmental Effects Evaluation and to secure funding when decision making. When it comes to disaster management, the Ministry of Safety and Public Affairs and the National Emergency Management Agency participate in the dam construction policy processes.

Fourth, likewise we experienced the yearlong disputes over compensation for the residents in the submerged area in Hantan River dam conflict. It is necessary to enact related Acts to develop long-term measures for them. Lastly, it is also providing support to develop standard manual for conflicts for disaster respondents.

\section{References}

[1] Blount, S., and Larrick, R. P., Framing the game: Examining frame choice in bargaining. Organizational Behavior and Human Decision Processes, 81(1), 43-1, 2000. 
[2] Cupach, W. R., and Canary, D. J., Competence in Interpersonal Conflict, Prospect, IL: Waveland Press, 1997.

[3] Drake, L. E. and Donohue, W. A., Communication Framing Theory in Conflict Resolution, Communication Research, 23(3), 297-322, 1996.

[4] Ehrmann, J. R. and Stinson, B. L., Joint Fact- Finding and the Use of Technical Experts, In The Consensus building Handbook: A Comprehensive Guide to Reaching Agreement. Edited by L. Susskind, S. McKearnan, and J. Thomas-Larmer, Thousand Oaks, CA: Sage, 1999.

[5] Folger, J. P., Poole, M. S., and Stutman, R. K., Working through conflict: A Communication Perspective (4th ed.), New York: Longman, 2001.

[6] Gray, B., Purdy, J. M., and Bouwen, R., Comparing Dispositional and Interactional Approaches to Negotiating. Paper Represented to the Annual conference of the International Association for Conflict Management, Vancouver, Canada, 1990.

[7] Lewicki, R. J., Barry, B., Saunders, D. M., and Minton, J. W., Negotiation (4th ed.), New York: McGraw-Hill, Irwin, 2003.

[8] Ozawa, Connie P., Recasting Science: Consensual Procedures in Public Policy Making, Boulder, CO: Westview Press, 1991.

[9] PCSD, A Report on Activities of the Task Force Team for Hantan River Dam Conflict Management, 2004.

[10] Pinkley, R. L, Dimensions of Conflict Frames: Relation to Disputants Perceptions and Expectations, International Journal of Conflict Management, 3, 95-114, 1992.

[11] Putnam, L. L., and Holmer, M., Framing, Reframing, and Issue Development. In Putnam, L. L. and Roloff, M. E. (Eds.), Communication and negotiation (pp. 128-155), Newbury Park, CA: Sage, 1992.

[12] Randall G. R., Conflict Framing Categories Revisited, Communication Quarterly, 54(2), pp. 157-173, 2006.

[13] Sillars, A. L., Roberts, L. J., Dun, T., and Leonard, K. E., Stepping into the Stream of Thought: Cognition during Marital Conflict, In V. Manusov and J. H. Harvey (Eds.), Attribution, Communication, and Close Relationships, pp. 193-210, Cambridge, UK: University Press, 2000. 